\title{
Location Quotient Technique and Economy Analysis of Regions: Tabuk Province of Saudi Arabia as a Case Study
}

\author{
A.K. Alhowaish ${ }^{1}$, Alsharikh, M.A ${ }^{2}$, Alasmail, M.A ${ }^{3}$, Alghamdi, Z.A ${ }^{4}$ \\ ${ }^{1}$ Corssponding Author: A.K. Alhowaish, Associate Professor, University of Dammam, \\ College of Architecture and Planning, Department of Urban and Region Planning, \\ P.O. Box 2397, Dammam 31451, Saudi Arabia \\ ${ }^{2,3,4}$ Master Students at University of Dammam, College of Architecture and Planning, \\ Department of Urban and Region Planning, P.O. Box 2397, Dammam 31451, Saudi Arabia, Email:
}

\begin{abstract}
Saudi Arabia has experienced an extensive economic growth after the oil revolution [1], which still remains the main source of economy in Saudi Arabia[2]. In alignment with the kingdom efforts to diversify its economical bases, all 13 regions were supported including Tabuk province[3]. The research is studying the economic activities within Tabuk region and particularly the one having "high localization rate" and suggest the Ministry of Economy and Planning to focus on these sectors which will help to enhance Tabuk's economic growth within the regional network and to support the national economy. this research is divided into five parts, an introduction, literature review, research methodology, results and conclusion and finally the recommendations.
\end{abstract}

Keywords: Location Quotient, Economic Analysis, Tabuk Region, Saudi Arabia.

\section{Introduction}

Tabuk province is located in the Northwestern part of the Kingdom of Saudi Arabia, at the intersection of longitude 26.35 East longitude and 28.32 North. It includes several districts with total area more than $120,400 \mathrm{~km} 2$ that represents more than $6 \%$ of the area of the Kingdom. Tabuk province population estimated about 803,418 [4].

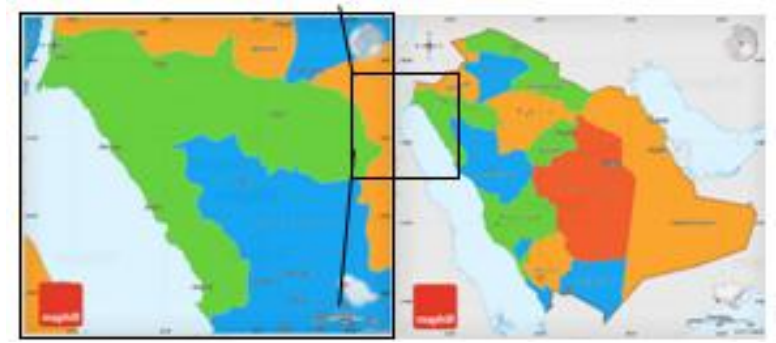

Picture 1 Tabuk province location [5].

Table 1: Economic Activity in Tabuk province

\begin{tabular}{|c|c|c|c|}
\hline No. & Economic Activity & No. & Economic Activity \\
\hline 1 & $\begin{array}{c}\text { Agriculture, forestry and } \\
\text { fishing }\end{array}$ & 12 & Real estate activities \\
\hline 2 & Mining and quarrying & 13 & $\begin{array}{c}\text { Professional, scientific and } \\
\text { technical activities }\end{array}$ \\
\hline 3 & Manufacturing & 14 & $\begin{array}{c}\text { Administrative and support } \\
\text { service activities }\end{array}$ \\
\hline 4 & $\begin{array}{c}\text { Electricity, gs, steam and } \\
\text { aire conditioning supply }\end{array}$ & 15 & $\begin{array}{c}\text { Public administration and } \\
\text { defence; compusory social } \\
\text { security }\end{array}$ \\
\hline 5 & $\begin{array}{c}\text { Water supply; swerage, } \\
\text { waste management and } \\
\text { remediation activities }\end{array}$ & 16 & Education \\
\hline 6 & Construction & 17 & $\begin{array}{c}\text { Human health and social } \\
\text { work activities }\end{array}$ \\
\hline 7 & Wholesales and retail & 18 & Arts, entertaintment and \\
\hline
\end{tabular}

\begin{tabular}{|c|c|c|c|}
\hline & $\begin{array}{c}\text { trade; repair of motor } \\
\text { vehicles and motorcycles }\end{array}$ & & recreation \\
\hline 8 & $\begin{array}{c}\text { Transportation and } \\
\text { storage }\end{array}$ & 19 & Other service activities \\
\hline 9 & $\begin{array}{c}\text { Accommodation and } \\
\text { food service activities }\end{array}$ & 20 & $\begin{array}{c}\text { Activities of households as } \\
\text { emplyers; undifferentiated } \\
\text { goods-and sersvices- } \\
\text { producing activities }\end{array}$ \\
\hline 10 & $\begin{array}{c}\text { Information and } \\
\text { communication }\end{array}$ & 21 & $\begin{array}{c}\text { Activities of extraterritorial } \\
\text { organizations and bodies }\end{array}$ \\
\hline 11 & \multicolumn{2}{|c|}{ Financial and insurance activities } \\
\hline
\end{tabular}

Since those sectors are not interfering with each other and developing some of them without any benefits, this research will come out with some recommendations that will guide economic planners to focus on and support the unique activities which will enhance Tabuk economy and hence the kingdom. Tabuk province was focused on because of its scarcity of studies particularly the economic ones. Even though it is the North gate of the Kingdom of Saudi Arabia, and has many attractions including tourism, industrial, commercial, and urban renaissance [6].

\section{Literature Review}

\subsection{Definitions}

- Economic: connected with the trade, industry and development of wealth of a country, an area or a society [7]

- Regional Economic: To provide regional \& local policymakers with simple and easy to use tools that will assist them in describing and documenting changes in their regional and local economy in a way that enables them to make sound and informed decisions [8]. 


\section{International Journal of Science and Research (IJSR) \\ ISSN (Online): 2319-7064}

Index Copernicus Value (2013): 6.14 | Impact Factor (2014): 5.611

- Percentage Share: Employment sector concentration ratio compared to other sectors, which means the total employment in the sector [9].

- Location Quotient: probably responsible for the long life and continuing popularity and use of economic-base multipliers. These quotients provide a compelling and attractive method for estimating export employment [10].

- Multiplier Effect: Another approach which has been used in estimating economic-base multipliers is to fit a multipleregression equation to regional data. The first of these studies arose in a study of the impact of military bases on Portsmouth, New Hampshire in 1968 by Weiss and Gooding (Weiss and Gooding 1968) [10].

\subsection{Case studies}

In economic researches, economic planners uses several equations and methods which benefit the economy and its activities at the national, regional and local levels. In addition, Planners are extracting figures that give important economic implications based on which the direction is use those figures analysis in the economic support. One of these researches is ECONOMIC TRENDS OF SAUDI URBAN SYSTEM for Abdulkarim K. Alhowaish and Faez S. Alshihri which used HI index to measure the level of diversification/specialization of an economy in Saudi Arabia, The data for this research paper were obtained from the Annual Statistical Report of the Saudi General Organization for Social Insurance (GOSI) for the years 1992 and 2010. and comes out with this results: - Over the period from 1992 to 2010, the level of specialization/diversification, as measured by HI, did not change much for the average Saudi urban system. The urban system as a whole, changed slightly from 0.18 to 0.24 respectively. - In 2010, 63 percent of Saudi urban areas were diversified to the extent that their HI was less than 0.29. This was a decrease from 79 percent in 1992. - between 1992 and 2010. The result revealed that all urban areas witness an increase in their workforce over the period of analysis, 32 percent of them were in the more desirable position of having a diversifying economy while 68 percent were in a position if having a specializing economic structure [11].

Another research City of Brampton: Issues Affecting the Manufacturing Sector, from The Centre for Spatial Economics in association with Interkom Creative Marketing September 15, 2005, using LQ technique to construct a set of industrial location quotients for the City of Brampton. the data for this research paper were obtained from the City of Brampton for 2003 economic base industries based on the Census data for 1996 and 2001:. the research paper comes out with this results by using SWOT analysis : - Power: 1) City Location: Near the US cities that have critical works 2) Network Transportation: Network Highways linking companies 3) Social Life: Low crime rate 4) Land Availability: A large inventory of industrial and residential lands. and for - Weakness: - The high value of Canadian dollar. - High interest rates at local banks - Raising in commodity prices - The lack of hotels due to the governmental support. - Opportunities: - Manufacturing groups in the city were witnessing rapid growth over the past years and this was expected to continue. Hence, the existing supporting services had grown as a result of this new activities. - Risks: - In the event of economic growth and manufactures expanding in the city, the real estate risk would affect the population presence in the city. - The cost of performing business and interest rates. - Risk of the new laws to impose new fees. - Traffic congestion was expected in the future [12].

\subsection{Spatial Economic Effect}

and other studies shows that it has been the discussion subject of spatial economic development in the Kingdom of Saudi Arabia in the past three decades. And it touched on several different topics, including those who tried to formulate strategies and policies of comprehensive spatial development where they have put the overall architectural strategy of the Kingdom, and to achieve balanced development with all aspects social, economic and environmental and the development of a proposed strategy for spatial development in the Saudi Arabia, With three main axes represented the social dimension, economic dimension and architectural dimension [13], and make strategy for Spatial Rural Development in Saudi Arabia which is Reducing intensity of spatial variation Between urban and rural areas within the same region [14], some topics are going to pursuance Some theoretical concepts in the study of spatial development Where they focused on study the concept of the center - margin in Saudi Arabia According to environmental perspective And the role of development plans In management the regional balance in the Kingdom, especially the concept of attraction, center and margins[15], and pursuance Saudi urban system on Central concept And its role to acceleration The balance between the regions of the Kingdom of Saudi Arabia [16]. and another one its present analysis The intensity of regional disparities in Saudi Arabia, It has discussed the impact of Spatial distribution of industries In the Kingdom of the regional disparities[17]. While It was discussed Spatial development in two administrative areas al-Sharqiya and Medina and Role of Petrochemical Industries In the industrial city of Jubail and Yanbu In the development of the administrative regions mentioned above [18]. The debate on the spatial distribution of the thirteen regions of the Kingdom [19]. And regional disparities of health services in the kingdom [20]. And the role of small and medium sized cities in the spatial development of the Kingdom [21].

The previous studies is Show us number of important points in this study, Where most of this studies and analysis its for a wide spatial units, such as five planning territories in the kingdom of the thirteen administrative regions in the Kingdom, we do not find any study consist to one spatial unit or one administrative region, except study for Al-Sharqiya and Medina[22]. The main recommendations of these studies indicate that future studies should be at the level of administrative regions and the provinces associated with them, to gives more accurate results and more detailed Around spatial economic development in the regions of the Kingdom, and this is what will be done by this study. 


\section{International Journal of Science and Research (IJSR) \\ ISSN (Online): 2319-7064}

Index Copernicus Value (2013): 6.14 | Impact Factor (2014): 5.611

\section{Research Methodology}

Some equations will be applied to the economic activities in the Tabuk region to help getting the results, through which we can reach economic policies of Tabuk. From these equations:

Percentage Share:

$$
\% \text { share }=\frac{e i}{e}
$$

\section{Location Quotient}

$$
L Q=\frac{e i / e}{E i / E}
$$

Multiplier Effect

$$
\text { BEir }=\left\lfloor 1-\frac{1}{L Q i}\right\rfloor * \text { Eir }
$$

Where: $\mathrm{e}_{i}=$ Local employment in industry $\mathrm{i}$, e =Total local employment, $\mathrm{E}_{i}=$ Reference area employment in industry $\mathrm{i}$, $\mathrm{E}=$ Total reference area employment, $\mathrm{LQ}_{i}=$ basic employment in industry $\mathrm{i}$ in region $\mathrm{r}, \mathrm{BE}_{i r}=$ location quotient in industry $\mathrm{i}, \mathrm{E}_{i r}=$ employment in industry i, region $\mathrm{r}$ [7], [8]. This equations depends on the knowledge of key economic sectors which were the exporting sectors of the region bring income from abroad investment. Hence, the region is selfsufficient and an exporter of the sector's economic fundamental and nonessential while supporting key sectors and be self-sufficient and attracts deficit from outside the region.

The information is calculated on a specific time period (2015), where calculation of percentage share in every sector of the economic sectors in the Tabuk region compared to other sectors. Then, knowing the percentage share in every sector of economic sectors in the Kingdom and compare it with the rest of the economic sectors ratio. After that, finding out Location Quotient(LQ) by finding out the result of the concentration ratio of the economic sector in Tabuk and compare it with the rest of Saudi. Finally, knowing the basic and non-basic economic sectors by the following equation:

- Location Quotient (LQ)> $1=$ basic economic sector.

- Location Quotient (LQ) $<1$ = non- basic economic sector.

and do the Multiplier Effect ratio To determine how many employees working in the non-basic sectors, we subtract the number of all employees in each sector of the main sectors in the province with the number of employees working in the basic sector. And then find out the number of jobs that would be created by the basic sectors in the rest of the economic sectors in the region through knowledge of influencing factor by dividing the number of employees in the economic sector in the region divided by the number of basic employees in the same economic sector.

This contributes to know the basic sectors of the economy and develop it in the region. Also, to find economic sectors that would make a strong regional economy. Moreover, to identify the basic economic sectors that are cable to export and make the economic sectors stronger in the region, and find out the weak economic sectors there.

\section{Analysis and Results}

When extracting the percentage share in Saudi Arabia and Tabuk province, the below figure is shown:

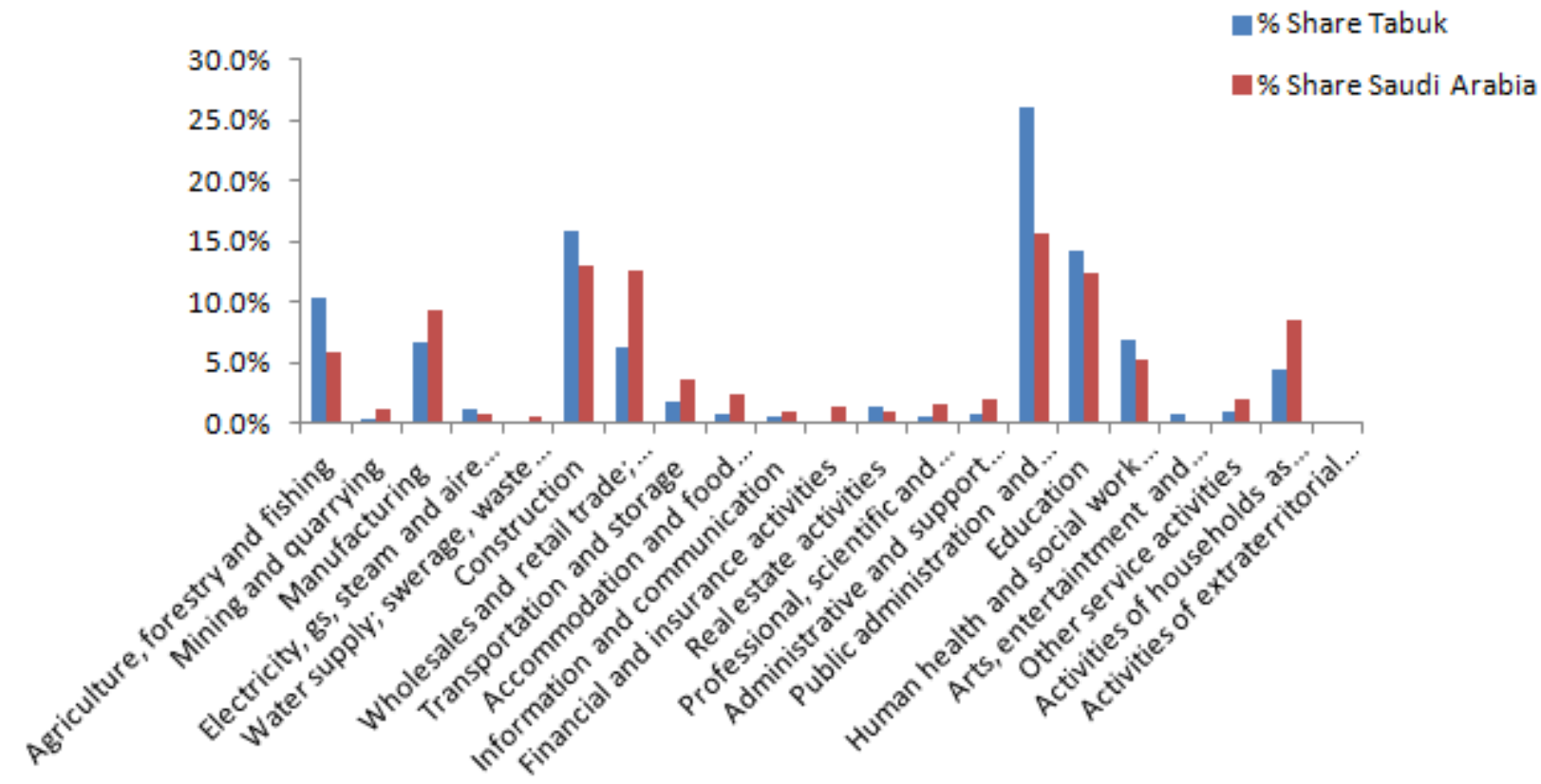

Figure 1: Percentage Share in Saudi Arabia and Tabuk province

We found that the following sectors are the highest percentage share concentration in the whole country. Most of these sectors are the service sectors, sectors with number $15,16,17,4$ and 18 take the biggest ratio of Tabuk, and then the real estate sector (construction and real estate) and finally one productive sector which is the agriculture and fishing sector.

\section{Volume 4 Issue 12, December 2015}




\section{International Journal of Science and Research (IJSR) \\ ISSN (Online): 2319-7064 \\ Index Copernicus Value (2013): 6.14 | Impact Factor (2014): 5.611}

Table 2: Percentage share in Saudi Arabia and Tabuk

\begin{tabular}{|c|c|c|}
\multicolumn{3}{c}{ province } \\
\hline $\begin{array}{c}\text { Sector } \\
\text { No. }\end{array}$ & $\begin{array}{c}\text { Percentage } \\
\text { share Tabuk }\end{array}$ & $\begin{array}{c}\text { Percentage share Saudi } \\
\text { Arabia }\end{array}$ \\
\hline $\mathbf{1 5}$ & $26.1 \%$ & $15.7 \%$ \\
\hline $\mathbf{6}$ & $15.9 \%$ & $13.0 \%$ \\
\hline $\mathbf{1 6}$ & $14.3 \%$ & $12.3 \%$ \\
\hline $\mathbf{1}$ & $10.3 \%$ & $5.8 \%$ \\
\hline $\mathbf{1 7}$ & $6.8 \%$ & $5.2 \%$ \\
\hline $\mathbf{1 2}$ & $1.4 \%$ & $1.0 \%$ \\
\hline $\mathbf{4}$ & $1.1 \%$ & $0.7 \%$ \\
\hline $\mathbf{1 8}$ & $0.8 \%$ & $0.2 \%$ \\
\hline
\end{tabular}

(see Table 1: for Economic Activity in Tabuk province)

By applying Location Quotient equation on the economic sectors in the region, it was observed that the same sectors that received the highest localization rate in the region compared to the state was the economic sectors. This gives us an indication that whenever the regional LQ was higher than the one in the kingdom, it will be a basic sector.

Table 3: LQ for economic Activities in Tabuk province

\begin{tabular}{|c|l|}
\hline Sector No. & LQ \\
\hline 18 & 5.39 \\
\hline 1 & 1.80 \\
\hline 4 & 1.71 \\
\hline 15 & 1.66 \\
\hline 12 & 1.43 \\
\hline 17 & 1.32 \\
\hline 6 & 1.22 \\
\hline 18 & 5.39 \\
\hline
\end{tabular}

(see Table 1: for Economic Activity in Tabuk province)

Table 3 shows us that the sector No. 18 received the highest LQ rate. This was followed by sectors number $1,4,15,12$, 17 and finally sector No. 6 with less localization coefficient. By analyzing the general situation between the concentration ratio and $L Q$, it is obvious that the economic sectors in the Tabuk region is divided into the following table according to their importance and then spitted to groups to facilitate the regional economic policies.

The number of basic employment in Tabuk is 66,757 divided among the number of economic sectors in Table 6 which is equivalent to $23 \%$ of the total employment in Tabuk.

Table 4: Basic and Non-basic Employment

\begin{tabular}{|c|c|}
\hline Sector No. & Basic Employment \\
\hline 15 & 30,192 \\
\hline 6 & 13,330 \\
\hline 16 & 8,281 \\
\hline 17 & 5,688 \\
\hline 18 & 4,786 \\
\hline 4 & 1,921 \\
\hline 12 & 1,373 \\
\hline
\end{tabular}

(see Table 1: for Economic Activity in Tabuk province)

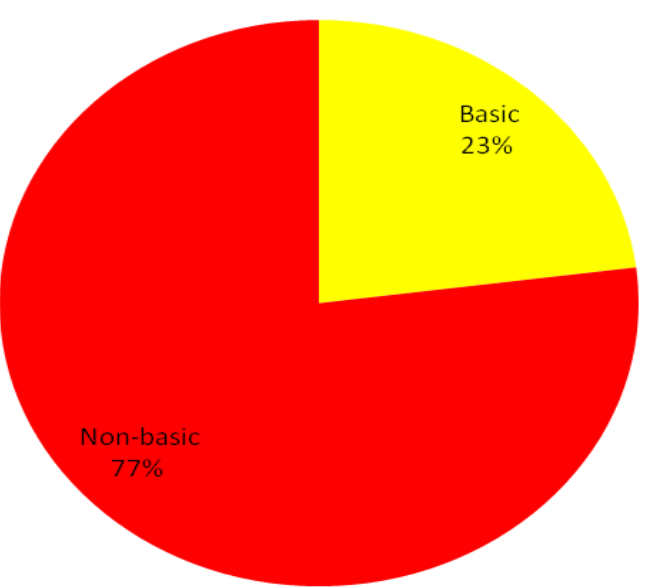

Figure 2: Basic and Non-basic Employment

The main sectors number of basic and non-basic employment shows that the economic sector 15, won the largest proportion although it doesn't get a high coefficient of resettlement due to the high number of employment out of the total employment in the region. This is also an indication that Tabuk service sectors controls the basic economy.

Table 5: Basic and Non-basic Employment

\begin{tabular}{|c|c|}
\hline Sector No. & Multiplier Effect \\
\hline 16 & 7.31 \\
\hline 6 & 5.57 \\
\hline 17 & 4.15 \\
\hline 12 & 3.35 \\
\hline 15 & 2.51 \\
\hline 4 & 2.41 \\
\hline 1 & 2.25 \\
\hline 18 & 1.23 \\
\hline
\end{tabular}

(see Table 1: for Economic Activity in Tabuk province)

Table 5 shows us that the highest multiplier effect is the education sector with 7.31 which means that every function in the education sector provides 6.31 jobs in other economic sectors in Tabuk. The second highest multiplier effect is the construction sector with 4.35 rate as a total which means every function in basic sectors in Tabuk provide 3.35 number of jobs in Saudi Arabia.

From the previous conclusions, sectors will be divided as a clusters according to the location quotient, Percentage shear and multiplier effect. 


\section{International Journal of Science and Research (IJSR) \\ ISSN (Online): 2319-7064}

Index Copernicus Value (2013): 6.14 | Impact Factor (2014): 5.611

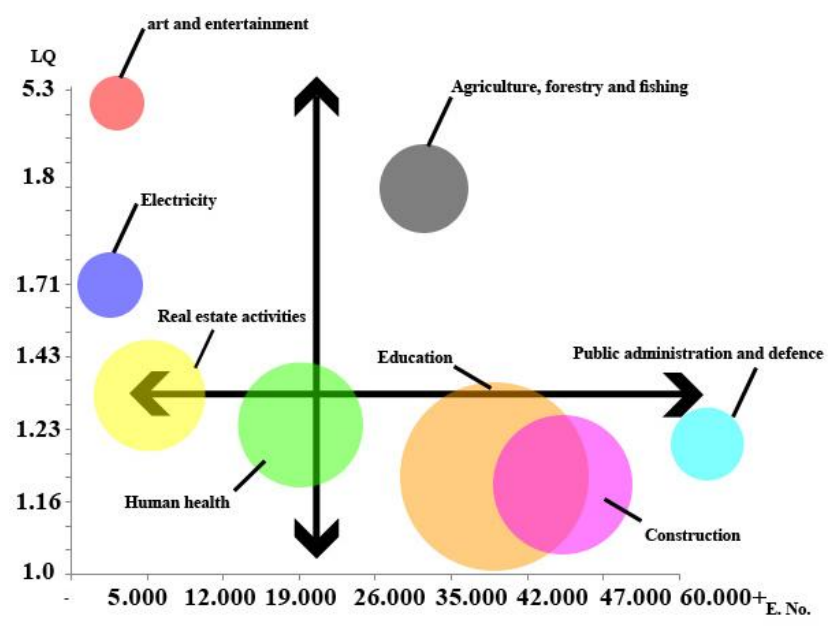

Figure 3: Basic Sector cluster analysis

Also, it was noted that the service sectors are associated with high localization rate, high labor and provide more jobs. In addition, sectors will be divided into groups for which the development of the sectors will be for the most important to Low sectors.

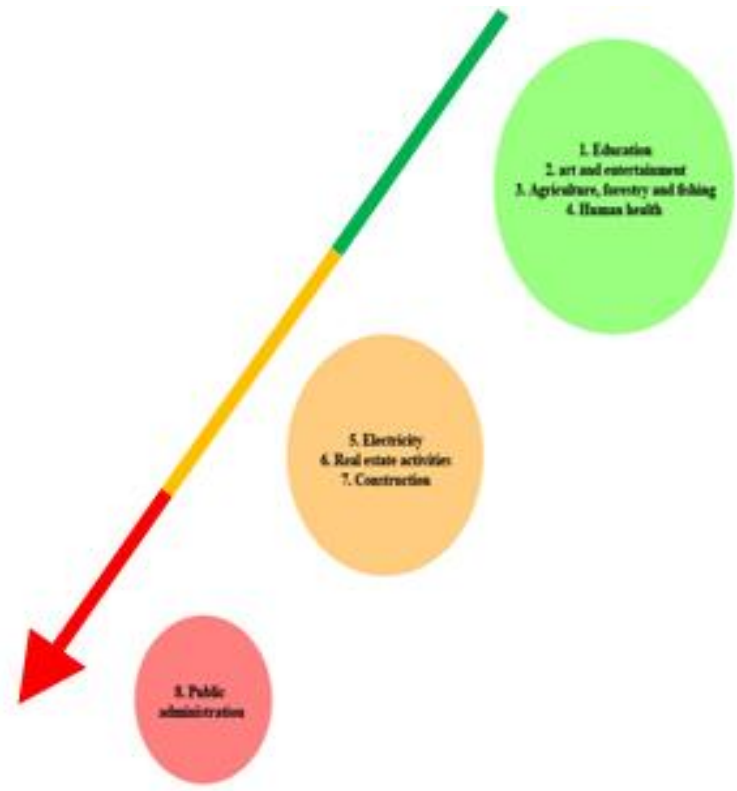

Figure 4: Important sector cluster

We discovered that the Tabuk is serving region, and must be dealt with as a self-serving area, self-sufficient and export services to the rest of the surrounding areas.

\section{Conclusion and policy recommendation}

- Tabuk economy is serving economy and not production one. Based on the current status, basic manpower concentration was in the service sectors was $66 \%$, meaning that the economy region depends on the export of basic human resources.

- Figure 4 shows us that the group with first economic power includes activities such as "education, art, tourism, agriculture, fishing and health" This gives an indication that the region has the elements of healthy and educational tourism.
- Tabuk region faces two possibilities: a) support serving sectors and make the Tabuk region's economy more specialized. B) support the productive economy and make the Tabuk region's economy more diverse.

- strength of the healthy and educational sectors is an index of the strength of education in the Tabuk region, and this makes the proposal to support the University of Tabuk an excellent proposal. Moreover, the strength of the tourism, agriculture and fishing sectors is an indication of the land nature strength in the region, and this supports the the coastal strip and exploitation optimum exploitation proposal and the creation of facilities for fishing the arena through basic artechalture sector in the region.

- There is an opportunity for tourisms cooperation between the State of Jordan and Tabuk province on what we call "fads province" near the Red Sea and lies about $30 \mathrm{~km}$ from the Gulf of Aqaba and includes the effects, in Arabic tourism project.

- The focus on serving-economy and the creation of an employment and professional training centers which will help Tabuk to export more human resources in the Kingdom.

\section{References}

[1] A. Aldakhil, The Economic Development of Kingdom of Saudi Arabia, Dar Alsaqi Press, Riyadh, 2011

[2] M. Aldagheiri, Economic Diversification in Resource Abundant Economies: The Case of the Minerrals Industry in Saudi Arabia, the mining industry in the Kingdom of Saudi Arabia as a case study, LAMBERT Press, Saarbrucken, 2012.

[3] H. Nazer, "The First Development Plan 1970-1975" report 1, Ministry of Economy and Planning, Riyadh, Saudi Arabia, 1969

[4] M. Alshmari, "General Census of Population and Housing " report 4, central department of statistic and information, Riyadh, Saudi Arabia, 2010.

[5] The web's largest map gallery, "Tabuk Map Location " www.maphill.com, para. 1, Oct. 4, 2013. [Online]. Available: http://www.maphill.com/saudiarabia/tabuk/simple-maps/gray-map/cropped-outside. [Accessed: Nov. 20, 2015].

[6] Tabuk, Municipality, "About the Tabuk " tabukm.gov.sa, para. 1, Oct. 4, 2013. [Online]. Available:

http://www.tabukm.gov.sa/OurGeography.aspx. [Accessed: Nov. 20, 2015].

[7] Oxford University, The Oxford English Dictionary , oxford University Press, oxford, 1986.

[8] M. Dinc, "Regional and Local Economic Analysis Tools" report 1004, World Bank Institute, Washington, DC, United States of Americ

[9] F. Aburadi,"spatial distributions - study in ways of statistical description and numerical analysis in geography," University Knowledge House, Alexandria, 1991.

[10] W.A. Schaffer, "Economic-Base Theory," in Regional Models of Income Determination, New York, 2010

[11] A. K. Alhowaish, \& F. Al-shihri, "economic trends of saudi urban system (1992 - 2010)," Journal of 
International Business Studies, XXIII (4), pp. 216-225, 2013

[12] The Centre for Spatial Economics in association with Interkom Creative Marketing, "City of Brampton: Issues Affecting the Manufacturing Sector " KanGAL report 200001, The City of Brampton Economic Development, Brampton, Canada, 2005.

[13] M. Abdulrahman, and V. Almarikhi, and A. Alkhudari,"Urban Development Strategy of Kingdom of Saudi Arabia," in book of Urban Development in Saudi Arabia: Opportunities and Challenges, edited by Salih Hathloul and Narayanan Aadadan, Dar Alshn: Riyadh, 1989.

[14] A. K. Alhowaish, "The Saudi system of rural and urban national strategy: an analytical study of the population of rural communities in the eastern region," Building Technology magazine, 12.23: 28-43, 2011.

[15] M. Mushkhus, "Role of development plans in managing regional balance in Kingdom of Saudi Arabia: Evaluation Study to regional experience of Kingdom between the years 1970-1994," Geography Research, Saudi Geographical Association, 21.36: 78-112, 2001.

[16] A. K. Alhowaish, "the Saudi regional urban system and the concept of the central place: analytical study of the concentrations of population in the eastern region," Building Technology Magazine, 9.20: 26-37, 2010.

[17] M. Abdulrahman, V. Almarikhi, and A. Alkhudari,"urban development strategy of the Kingdom of Saudi Arabia", in the book of Urban Development in Saudi Arabia: Opportunities and Challenges, edited by Salih Hathloul and Narayanan Aadadan, Dar Alshn: Riyadh, 1989.

[18] M. Mushkhus, "Role of Petrochemical Industries in regional development in Alsharqiya and Medina regions in Saudi Arabia: assessment study of the experiment of Jubail and Yanbu cities according to growth pole theory ,', Journal of the Faculty Arts and Sciences, King Abdul Aziz University, 18.36: 78-112, 1998.

[19] A. Howaish,"spatial variation of health services in the Kingdom of Saudi Arabia: an analytical study of the period between 1992 to 2009", Journal of the Gulf and Arabian Peninsula Studies, University of Kuwait, accepted for publication in the July 3, 2013.

[20] A. . Al-Jarallah, and M. Aldioufi,"the regional variation in the Kingdom of Saudi Arabia: an analysis of the labor environment", Journal of Documentation and Humanities Research Center, Qatar University, 10.22: 76-98, 1998.

[21] M. Mackie,"size distribution of cities in Saudi Arabia," a symposium of Saudi cities: its spread and internal installation. Department of Geography. King Saud University, Riyadh, 1983.

[22] S. Mackie "small cities are the hope of the future: Hano Mano Madin-balanced: An Empirical Study on Saudi Arabia,' the Arab Journal for Humanities, 8.31: 34-78. 1988. 